\title{
Catástrofes y periodismo: el relato, los escenarios, las interacciones y las necesidades prácticas y psicológicas de todos los implicados
}

\author{
Pepe RodRíGUEZ \\ Universidad Autónoma de Barcelona \\ pepe.rodriguez@uab.cat \\ Begoña OdRIOZOLA FARRÉ \\ Departamento de Salud de la Generalitat de Catalunya. \\ Área de Psicotrauma. Servicios Integrales de Psicología (SIPS) \\ b.odriozola@sips.cat
}

Recibido: 12 de marzo de 2012

Aceptado: 28 de septiembre de 2012

\begin{abstract}
Resumen: Este trabajo analiza críticamente la construcción del relato periodístico de catástrofes, expone la estructura operativa básica en escenarios de emergencias y las necesidades prácticas y psicológicas de todos los implicados y sus interacciones, enfatizando las que atañen a víctimas y periodistas. El análisis revisa la literatura especializada y se fundamenta en la experiencia acumulada por los autores, desde 2005, en los equipos de intervención del Sistema de Emergencias Médicas de Cataluña y en el intercambio profesional con otros equipos de emergencias estatales. Se analiza los problemas psicosociales que la información periodística inadecuada puede provocar en los afectados, especialmente la victimización y la traumatización secundaria, y también la falta de capacitación, profesional y de autoprotección, de los periodistas que cubren esos sucesos y los problemas de estrés postraumático que pueden padecer.

Palabras clave: periodismo, catástrofe, víctima, trauma, estrés postraumático.
\end{abstract}

\section{Disasters and journalism: the report, settings, interactions and practical and psychological needs of all implicated}

\begin{abstract}
This paper analyzes critically the construction of journalistic report of disaster, explains the basic operating structure in emergency settings beside interactions and practical and psychological needs of all involved, emphasizing those that concern victims and journalists. The analysis reviews the specialized literature and is founded on the experience accumulated by the authors, since 2005, on the intervention teams in the Medical Emergency System of Catalonia and the professional exchange with other state emergency teams. The psychosocial problems that inappropriate media coverage may cause to the victims are analyzed, especially victimization and secondary traumatization, and also the lack of professional and self-protection training of journalists covering these events and posttraumatic stress problems that they may suffer.
\end{abstract}

Keywords: journalism, disaster, victim, trauma, posttraumatic stress.

Referencia normalizada: RODRÍGUEZ, Pepe y ODRIOZOLA FARRÉ, Begoña (2012): “Catástrofes y periodismo: el relato, los escenarios, las interacciones y las necesidades prácticas y psicológicas de todos los implicados“. Estudios sobre el mensaje periodístico, vol. 18, núm. 2 (julio-diciembre), págs.: 577-594. Madrid, Servicio de Publicaciones de la Universidad Complutense.

Sumario: 1. Introducción. 2. Radiografía del periodismo de catástrofes; 2.1. La construcción del relato de catástrofes; 2.2. Del interés inicial al silencio final; 2.3. Responsabilidad social del periodista. 3. Los escenarios de catástrofes: roles profesionales e interacciones; 3.1. Necesidades de víctimas y familiares; 3.2. Necesidades de la comunidad; 3.3. Necesidades de las Fuerzas y Cuerpos de Seguridad; 3.4. Necesidades del Cuerpo de Bomberos; 3.5. Necesidades de los Servicios Médicos; 3.6. Necesidades de los psi- 
cólogos sanitarios y del personal psicosocial; 3.7. Necesidades de los periodistas; 3.8. Necesidades de los políticos. 4. Problemas detectados en el trabajo periodístico sobre catástrofes. 5. Discusión y conclusiones. 6. Referencias bibliográficas.

\section{Introducción}

Las catástrofes, ya sean originadas por causas naturales o por conductas humanas, acaparan la atención mediática por ser hechos graves y excepcionales. Previsibles o imprevisibles, generan incertidumbre y "cuanto mayor es la incertidumbre, mayores son las consecuencias y mayores las dificultades para trasladar los hechos al espacio y el tiempo de los medios" (BERNARDo y PELlisser, 2010: 108), pero esta dificultad no debe ocultarnos que el interés noticioso aumenta con la incertidumbre, "de ahí que los informadores estén interesados en sembrar incertidumbre sobre los hechos, para que se conviertan en mayor fuente de noticias" (GIL CALVO, 2003).

Cualquier catástrofe se convierte en un acontecimiento mediático cubierto en directo, especialmente por la televisión. Pero "analizar la mirada que la televisión da a la catástrofe no puede dejar fuera la estructura estética que conforma el tratamiento de la información, tanto en el contenido como en la forma. Es así como cada vez que la información sea espectacularizada a través de la intervención estética -como el uso de música incidental, la excesiva adjetivación con el fin de volver más emotiva la nota periodística o el uso de primeros planos de una persona sufriente-, necesariamente estaremos hablando de diversos niveles de vulneración de la dignidad de las personas" (OYANEDEl y Alarcón, 2010: 117).

Además de los datos que hacen comprensible el contexto y magnitud de una catástrofe, "siempre será imprescindible el relato minucioso de cómo la gente vivió ese momento, de lo que vio, oyó, sintió, supuso, imaginó y hasta soñó durante los días siguientes" (CAMPS y PAZOS, 1996: 196); y es en el relato testimonial cuando puede derivarse hacia el espectáculo y la vulneración de derechos personales.

Según una investigación sobre la televisión chilena, "el relato televisivo de la catástrofe se construye principalmente desde el dolor de las víctimas: su presencia corresponde al $49 \%$ del tiempo total destinado a las fuentes, quedando la presencia de fuentes oficiales -como gobierno, carabineros o fuerzas armadas- representada de manera muy secundaria (con porcentajes en torno al 16\%) y en el caso de los expertos, de manera marginal, cuyo tiempo total en pantalla se encuentra en torno al 3\% [...] las víctimas aparecen como personas anónimas, sin identidad propia [...] más bien constituyen evidencia empírica y anónima del dolor y la catástrofe [...] Al analizar el tratamiento audiovisual [...] se observa que los recursos más utilizados fueron la reiteración de imágenes (en el 48\% de las notas), el uso de primeros planos (44\%) ubicados espacialmente en un contexto de devastación material (frente a sus casas destruidas, dentro de las carpas, etc.)-, un uso excesivo de adjetivaciones (en más del $30 \%$ de las notas de carácter dramático) y la presencia de banda sonora (sobre el $20 \%$ de las notas) asociada principalmente a melodías tristes" (OYANEDEL y ALARCón, 2010: 120).

Josep María Royo, analista de la Escuela de Cultura de Paz de la Universidad Autónoma de Barcelona, hablando del "efecto CNN" -y su elocuente eslogan: "está pasando, lo estás viendo"-, afirmaba que "lo que vende es la inmediatez, el instante 
robado por un reportero que busca el lado más impactante de la actualidad [...] Se busca conmocionar al espectador, y no tanto explicar, informar, educar, analizar, comprender [...] Si sólo se publicitan las imágenes más duras intentando hacer un llamamiento a la pena, se genera lo que se llama la pornografía de los medios de comunicación" (FERNÁNDEZ, 2004).

Para algunos autores la televisión alimenta la fascinación por lo anómico y la catástrofe, integrando la tragedia "en discursos basados en la espectacularización de la realidad" (IMBERT, 2003: 167).

Pero cabe recordar que el periodismo de catástrofes es una especialidad delicada y compleja, pues el hecho afecta profundamente en lo emocional y material a muchos y a sus comunidades, alterando estructuras fundamentales -sociales, financieras, políticas, sanitarias, etc.- por tiempo indefinido. El campo de trabajo son escenarios caóticos y trágicos, con víctimas desoladas y desorientadas y equipos de emergencia que ponen orden y soluciones donde sólo hay necesidades urgentes. La primera fase de la emergencia puede durar horas o días y el dolor y el estrés hace mella en los afectados, pero también en los equipos técnicos y en los periodistas que trabajan sobre el terreno.

El periodista desplazado hasta escenarios de catástrofe ve lo evidente, pero inicialmente carecerá de fuentes adecuadas y sus datos serán parciales y subjetivos, cuando no falseados por intereses políticos. La información se organiza "sobre la base de testigos, supervivientes, las agencias informativas, otros medios de comunicación, estimaciones extraoficiales, rumores, policía, bomberos, protección civil y fuentes sanitarias. Se entrelazan caóticamente todos los discursos informativos como un reflejo de la situación excepcional" (RodRíGuEZ y MARTín, 2003: 572).

En esos escenarios puede ejercerse el periodismo de testimonio, explicando lo visto y vivido personalmente y lo relatado por protagonistas sobre el terreno. Pero algunas catástrofes dejan tanta devastación y dolor que el periodista testigo sucumbe a sus emociones y no logra apartarlas de su discurso informativo. Y si bien un distanciamiento emocional absoluto impide comunicar la magnitud del suceso y transmitir el sentimiento de las víctimas (CAMPS, 1999), la información debe ser objetiva y equilibrada y los periodistas deben cumplir las exigencias de su rol social en el trato con las víctimas, la elaboración de informaciones y la autoprotección física y emocional.

\section{Radiografía del periodismo de catástrofes}

Cuatro apuntes pueden introducir el modo cómo se realiza la información de catástrofes.

a) Según el contenido informativo: "los medios de comunicación no aportan información rigurosa [...] más bien facilitan el acceso de un gran número de gente que tele-experimenta la inestabilidad de manera simultánea" (LozANO, 2009: 241-242). La espectacularización predomina sobre la información.

b) Muchos autores -CAMPS (1999); Coté y Simpson (2000); Hight y SMYTH (2003) y QUESADA (2007)- recalcan que los sucesos deben narrarse con sensibilidad y estar contextualizados. Sensibilidad, empatía y rigor informativo son obligados para cubrir catástrofes. Lo escabroso no aporta información de calidad sino que revictimiza a los afectados. 
c) Atendiendo al impacto social se apunta que "los receptores de la información mediática de catástrofes están más acostumbrados a saber identificar fenómenos catastróficos que a saber comprenderlos [...] identifican tan sólo el aspecto más llamativo de las catástrofes: el trastorno [...] El hecho de [...] experimentar sin ser víctimas -a través de los telediarios y periódicos- las propensiones y las culminaciones catastróficas de los entornos próximos y lejanos, produce en los individuos una 'hipocondría generalizada"' (LozANo, 2002: 3). Un resultado muy alejado del periodismo responsable.

d) "Una vez que, con el paso del tiempo, se tiene mucha más información (contrastada y fiable) para explicar lo sucedido, la catástrofe va perdiendo el interés como noticia, ya no forma parte de las primeras páginas, ni de los titulares" (LOZANO, 2009: 235). El consumismo de sensaciones prima sobre el interés por conocer y comprender.

\subsection{La construcción del relato de catástrofes}

Los relatos periodísticos comienzan a construirse en escenarios dominados por el estupor y el caos, con escasa información contrastada. Intentan situar al receptor sobre el terreno y generarle una ilusión de experimentación directa, pero explican poco del contexto de la catástrofe y se caracterizan por ser un "goteo de datos que, con el paso del tiempo llega a convertirse en un gran torrente de información que desborda, por acumulación, la percepción y comprensión de lo que realmente ha ocurrido y está ocurriendo; [...] el testigo presencial o periodista que tiene la oportunidad de elaborar la reconstrucción narrativa delinea, porque no es posible hacer otra cosa en esos momentos, los aspectos más superficiales, llamativos, e incluso estéticos ('figuras catastróficas') de lo que ha sucedido en el centro del trastorno" (LOZANO, 2009: 241).

Al principio el relato proclama los efectos más directos -víctimas y daños materiales- avalado por el impacto descriptivo y emocional de las imágenes. Tras restablecerse un orden provisional por los equipos de intervención, el foco se traslada hacia supervivientes y afectados - para ponerle rostro al sufrimiento- $\mathrm{y}$ hacia los equipos de rescate, buscando su perfil más épico. Conforme va "enfriándose" el escenario, la noticia se desplaza hacia las tomas de posición de autoridades y organizaciones nacionales e internacionales y se presentan historias personales seleccionadas en un vano intento por prolongar el impacto emocional de un suceso cuyo consumo mediático ya decae rápidamente.

Pero el rigor informativo es escaso: "a pesar de la dificultad interpretativa del primer momento, los periodistas suelen cuantificar con rápidas impresiones, asegurar con efímeras observaciones y concluir con versiones insuficientemente contrastadas: la actualidad periodística se nos impone a todos como criterio. Más tarde, cuando las catástrofes se pueden medir — sin prisas - con datos más fiables y contrastados, ya han dejado de ser noticia" (LozANo, 2002: 3).

La banalización es norma: "las imágenes televisadas, convertidas en muchos casos en 'imágenes-espectáculo' [...] han sido presentadas de manera emocionante, destacando su componente solidario en detrimento del conflicto de fondo que resulta así banalizado" (LARRONDO, 2006). 
Y si la televisión espectaculariza la información sobre catástrofes, la prensa no hace mejor papel: "la información básica se sintetiza a través de un título de catástrofe $\mathrm{y}$ una foto de grandes dimensiones [...] [que] funciona como noticia y testimonio para ver o mirar la magnitud del hecho y comprobar la veracidad de los hechos [...] los titulares a grandes cuerpos, en negrita y muy gráficos, de estilo opinativo e interpretativo [...]. Es una narración abreviada de los hechos, pero muy gráfica y espectacular, de llamada al lector [...]. Existe una preponderancia del campo semántico vinculado con la tragedia [...]. En este tipo de situaciones extremas las fuentes utilizadas se basan tanto en las informaciones confidenciales, como en los rumores" (RODRÍGUEZ y MARTíN, 2003: 571-572).

Un estudio sobre la información de sucesos en la prensa española concluye que "el periodista recrea la vertiente emotiva y espectacular de la noticia, influido en buena medida por el deseo de atraer a un público que se define más como telespectador que como lector. Así, los textos planean sobre el mismo registro afectivo, sentimental, dirigiéndose al corazón y no a la razón. De hecho, brillan por su ausencia los textos analizados que tratan de contextualizar, interpretar y trascender el suceso, una de las funciones básicas del periodismo de calidad" (MARAURI et al., 2011).

\subsection{Del interés inicial al silencio final}

A cualquier catástrofe le sigue una conducta mediática similar. Al principio se fuerza un flujo informativo -con datos deficientes- tanto más desbordado cuanto mayor es la incertidumbre percibida. Progresivamente, el exceso informativo puntual -sumado al flujo cotidiano de "malas noticias"- satura la capacidad de procesamiento cognitivo de los receptores, pero también de los periodistas, que serán forzados a dejar el tema cuando pierda rentabilidad como reclamo de audiencia.

Los medios abandonan el lugar de los hechos "cuando el rendimiento icónico está agotado [...] cuando la inversión está amortizada, cuando los relatos dejan de cotizar en el mercado de las audiencias, cuando el drama se traslada del exterior (la calle), al interior de las residencias [...]. También, cuando la resistencia física y mental de los informadores desplazados a la zona se resiente, y cuando los gastos de mantenimiento de estos mismos equipos y los costos de transmisión superan el umbral que cada medio establece" (BERNARDO y PELLISSER, 2010: 111).

Lo que KAPUSCINKI (2000: 117) atribuye a la "nueva dramaturgia" de los medios conlleva consecuencias lamentables: "a medida que el interés del medio decrece, también lo hace el del público [...] si bien esta pérdida de interés informativo no hace desaparecer el problema [...]. De ahí que el desinterés de las organizaciones mediáticas en estos temas nos lleve a observar su incapacidad [...] para llevar a cabo una configuración informacional en base a los parámetros éticos que demanda el Periodismo. Un compromiso social pendiente de garantizar es que los medios ofrezcan una información integral y que ésta transmita de manera veraz y completa un acontecimiento, las causas que lo motivan y sus consecuencias" (LARRONDO, 2006).

\subsection{Responsabilidad social del periodista}

La responsabilidad social del periodismo es fundamental y, ante catástrofes, "ha de informar descubriendo contrariedades, según demanda hoy la complejidad del mundo 
global. Eludir esta responsabilidad y, por ende, el esclarecimiento de estos problemas contribuye a que desaparezcan de la realidad social [...] La adopción de posturas reduccionistas, dando a conocer los hechos para olvidarlos después, supondría la búsqueda de una emoción momentánea" (LARRONDO, 2006).

Algunos autores postulan la Responsabilidad Comunicativa de los medios como "agentes socioculturales ineludibles de la creación y afianzamiento de una ciudadanía crítica y comprometida precisamente a partir de la recepción e interpretación de una información compleja y responsable" (BERNARDO y PELLICER, 2010: 104).

Ante las catástrofes esta intermediación responsable es muy importante, ya que la complejidad que las caracteriza impide comprenderlas adecuadamente si falta un contexto informativo amplio y contrastado.

La informaciones no contrastadas convierten las hipótesis interesadas "en 'hechos', dando origen a toda una sarta de 'no-hechos', semejantes, que hacen innecesario aportar cualquier tipo de prueba" (ORTEGA, 2006: 47).

Encontramos ejemplos elocuentes en catástrofes ecológicas como las de Doñana o el Prestige; en ellas la prensa tuvo un triste papel dando pábulo a opiniones de "algunos científicos afines al poder para dar credibilidad a las decisiones políticas o para cargar con errores de ministros, a cambio de prebendas" (DE PABLOS y ELÍAS, 2003).

A esta evidencia cabe añadirle la "naturalización de los discursos mediáticos", que asumen una perspectiva determinista anclada en causas naturales y que elude otras concausas que "tienen que ver con la complejidad de factores que necesariamente han de ser considerados en una información adecuada cuyo objeto son tanto las causas como el desarrollo y los efectos" (BERNARdo y PELlisser, 2010: 104). El enfoque sesgado en lo natural/inevitable hurta el peso de lo humano/evitable que, desde parámetros políticos, económicos y socioculturales, contextualiza el hecho y permite comprenderlo en su complejidad y analizarlo desde las responsabilidades que pudieran haber junto al desencadenante natural.

Esta responsabilidad social incumplida por el periodismo se resalta en los trabajos analizados y bien puede resumirse así: "la información que entregan los medios de comunicación y particularmente la televisión en un contexto de catástrofe es fundamental para las personas en la medida que esta construye una narrativa que permite al sujeto situarse, conocer y dimensionar (en mayor o menor medida) la magnitud de un evento de tal naturaleza [...]. [Pero] la construcción narrativa que se aprecia [...] tiende al reforzamiento de estereotipos [...] la espectacularización y la presentación dramática de la información [...] el uso de recursos de producción tiende a exacerbar el impacto audiovisual y emocional, enfatizando el carácter del sujeto como un recurso objetal que, por cantidad e intensidad, es exhibido como representación del dolor [...] Esta imagen favorece una mayor victimización del sujeto [...] con el fin de evidenciar el impacto de la catástrofe" (OYANEDEl y Alarcón, 2010: 120-121).

\section{Los escenarios de catástrofes: roles profesionales e interacciones}

En una catástrofe se conforman escenarios complejos y caóticos donde interactúan los presentes (víctimas y testigos) y quienes, integrando equipos especializados o no, acuden al lugar. El reto de los equipos de intervención será evaluar daños y riesgos y 
establecer medidas de seguridad y protección para atender a las víctimas y luego iniciar acciones para dar respuestas a la comunidad.

Las necesidades de cada actor sobre el escenario son diferentes, siendo fundamental la coordinación. Tras una catástrofe se activan los planes de emergencia elaborados desde el Sistema Nacional de Protección Civil.

Los planes de Protección Civil nacionales establecen el marco organizativo básico que regula y posibilita el funcionamiento integrado de los servicios públicos y planes de actuación comunitarios ante catástrofes o accidentes con múltiples víctimas; también regulan el continuo de autoridades que eventualmente intervendrán en la gestión del suceso.

La coordinación de emergencias corresponde por ley a un mando único (Artículo 9 de la Ley $2 / 85$ sobre Protección Civil) y una vez activado el plan se establecen varios Centros de Mando. El Centro de Comandancia Avanzado (CCA) integra, sobre el terreno, a los técnicos coordinadores de cada grupo de actuación y a sus jefes naturales. El Centro de Coordinación Operativa (CECOP) apoya a la dirección de Protección Civil en la comunicación, coordinación y centralización de información entre los servicios de seguridad y el resto de equipos -y sus centros de coordinación-, autoridades, CCA y CRA (Centro de Recepción de Alarmas).

En incidentes con múltiples víctimas se habilita un Centro de Información, Atención y Reagrupamiento para familiares y afectados no heridos o heridos leves con alta médica. Se organiza en equipamientos municipales (polideportivo, centro cívico, escuela, etc.) alejados del escenario para proteger a los afectados de la sobreexposición de estímulos de la "zona cero" o lugar de mayor impacto traumático. En este espacio intervienen sanitarios, psicólogos, trabajadores sociales y voluntarios en labores de avituallamiento y gestión de necesidades básicas.

El centro de mando, establecido como comité de crisis, coordina las unidades situadas sobre el terreno, organizadas según funciones homogéneas, que son: sanitaria, intervención, logística y orden, así como las propias de grupos expertos en áreas específicas. La gestión eficaz de crisis requiere un abordaje integral, que cubra las necesidades y objetivos de los grupos intervinientes con perfecta coordinación y sin solapamientos.

Interactuar adecuadamente en medio de una catástrofe requiere que todos, también los periodistas, conozcan esta estructura organizativa y su funcionamiento.

Analizando las funciones que cada profesional debe cubrir, incluyendo a los periodistas, puede observarse en qué aspectos las necesidades de unos pueden solaparse o entrar en conflicto con las de otros.

Para presentar una relación básica de esas necesidades nos basamos en el análisis de la experiencia acumulada por los autores, desde enero de 2005, en los equipos de intervención del Sistema de Emergencias Médicas (SEM) de Cataluña y en el intercambio profesional con otros equipos de emergencias estatales.

El listado de necesidades de los diferentes actores en una catástrofe se presenta por orden de presencia o de llegada a los escenarios (aunque puede darse ligeras variaciones entre incidentes). 


\subsection{Necesidades de víctimas y familiares}

a) Seguridad. Antes que ayuda médica, las víctimas necesitan seguridad para que los daños no aumenten (por efecto de estructuras dañadas, violencia en curso, gases contaminantes...).

b) Ayuda médica inmediata.

c) Intimidad. Con la ayuda médica, y tras ella, debe proveerse intimidad, pues la sensación de estar expuesto a miradas ajenas, en situación de fragilidad, suele despertar sentimientos de vergüenza y vulnerabilidad (RODRíGUEZ et al., 2006: 131) que incrementan el daño psicológico y enlentecen la desactivación emocional.

d) Trato digno.

e) No ser retraumatizado. Evitar que concurran eventos asociados cuyo efecto previsible sea incorporar nuevas situaciones dolorosas a un contexto humano previamente traumatizado (MADARIAGA, 2002). "Se debe enfatizar el retorno a la normalidad tan pronto como sea posible, evitando la revictimización" (RoDRíGUEZ et al., 2006: 187). Debe protegerse especialmente a menores y a los más vulnerables.

f) Recibir mensajes que activen el canal racional para atemperar la intensidad emocional. Ante la amenaza abrumadora que implica el trauma, se activan las zonas cerebrales más instintivas junto al sistema límbico que gobierna la activación emocional. Para facilitar el procesamiento de la información que inunda el cerebro es preciso recibir mensajes que activen el canal racional (neocórtex) para atemperar la intensidad emocional (LEVINE y FREDERICK, 1999: 29-30). Si a una persona, en este estado, se le solicita ahondar en sus emociones o es sometida a estímulos emocionales - como hacen los periodistas y evocan sus informaciones-, el riesgo de retraumatización se incrementa.

g) Ser protegidos del protagonismo mediático no buscado y victimizador. Tras una vivencia traumática es común el estado de "congelación afectiva", de aturdimiento o embotamiento emocional, que son protectores del psiquismo; en este estado la víctima no es consciente de todo cuanto ocurre a su alrededor ni puede entender las demandas que recibe de otros -un periodista que la entrevista-, dando respuestas emocionales sin ser consciente de qué expresa. En estos casos puede alcanzarse un protagonismo mediático no buscado y, por ello, victimizador. Las víctimas deben ser protegidas de este riesgo y por eso los sanitarios -especialmente los psicólogos- alejan a los afectados de los periodistas.

h) Evitar quitarle importancia al suceso. Los afectados necesitan sentir que la prensa trata el suceso con rigor y seriedad, pero espectaculizarlo equivale a restarle importancia.

i) Centrarse en las estrategias de afrontamiento y en los recursos personales y sociales. Cuando las informaciones se centran en estos aspectos resultan de gran ayuda a las víctimas en su proceso de elaboración psicológica de la experiencia.

j) Ser mostrados autogestionando actividades en pro de mejorar la situación. Para las víctimas resulta muy útil y protector verse reflejadas afrontando su situación, aunque en los medios "difícilmente se los muestra autogestionando actividades en pro de mejorar la situación" (OYANEDEL y ALARCóN, 2010: 121). 
k) Recibir información práctica o útil para gestionar la situación.

1) Encontrar sentido a lo sucedido. Cada afectado necesitará encontrarle sentido a lo acontecido y mantener un recuerdo interiorizado e integrado de la experiencia.

m) Mantener el recuerdo. La información respetuosa sobre los allegados desaparecidos ayuda mucho a las víctimas, especialmente si ésta se prolonga más allá de 15 días tras la catástrofe.

\subsection{Necesidades de la comunidad}

a) Información. La comunidad necesita saber qué ocurrió (ACINAS, 2007: 314) y la recogida y transmisión de información es compleja para los servicios de emergencia, especialmente los listados de heridos y fallecidos. La necesidad periodística de inmediatez entra en conflicto con los servicios sanitarios, que no pueden/deben/quieren dar datos insuficientemente contrastados para evitar daños por noticias erróneas y evitar que los familiares se enteren por la prensa y no por profesionales que realizan las comunicaciones conteniendo las emociones y minimizando el impacto negativo. Cuando la prensa se adelanta se generan efectos psicológicos imprevisibles y puede lanzarse a muchas personas hacia los hospitales y/o Instituto de Medicina Legal y Forense de la zona, dificultando la gestión y el trabajo de los profesionales.

b) Orientación sobre qué hacer y cómo reaccionar. La comunidad necesita conocer las medidas de autoprotección para prevenir riesgos inmediatos y futuros. Precisa orientación para reaccionar ante la situación como parte de la gestión de crisis, que también es comunitaria.

c) Protección del contagio emocional. Una situación de dolor agudo y alta emocionalidad puede conllevar la activación emocional de víctimas y testigos, propiciando la traumatización secundaria o incluso movimientos incontrolados de grandes grupos sociales (HATFIELD et al. 1994).

d) Protección de la traumatización secundaria. Quienes no vivieron la experiencia traumática personalmente deben ser protegidos de la traumatización secundaria (DEKEL, 2010: 1928), del efecto doloroso y dañino que puede producirse por presenciar el trauma y ser testigo de la vivencia traumática ajena, algo especialmente agudo cuando la experiencia actual desencadena recuerdos de traumas pasados no plenamente procesados (RothSCHILD, 2006: 14-15). Las informaciones con alto contenido emocional aumentan el riesgo de traumatización, especialmente cuando hay factores de identificación, y aunque la imagen posee mayor potencial traumatizador (RoDRíGUEZ et al., 2006: 180), la descripción repetitiva de hechos terribles, en cualquier medio, incrementa el sufrimiento individual y colectivo (COTÉ y SIMPSON, 2000: 107-122), especialmente en menores (Otto et al., 2007).

e) Entender qué ha sucedido. "Desde el ámbito de la comunicación, se puede ayudar para que la población pueda comprender la dimensión del riesgo, identificar las zonas de peligro y conocer las medidas para prevenir, mitigar y enfrentar de mejor manera un desastre; de esta forma, se contribuye a reducir el temor y 
la aflicción, evitar la desorganización y aliviar el sufrimiento de las personas afectadas" (RoDRíGUEZ et al., 2006: 170).

f) Modificación de estructuras para prevenir futuros sucesos similares. La comunidad necesita conocer los medios de que se dispone o dispondrá para prevenir riesgos futuros.

g) Solución de posibles desequilibrios sociales que hayan podido contribuir al suceso. Se necesita conocer que los políticos trabajan gestionando la crisis y solucionando los desequilibrios sociales relacionados con la catástrofe.

h) Evitar estereotipos sociales de discriminación, desigualdad o conflicto.

\subsection{Necesidades de las Fuerzas y Cuerpos de Seguridad}

a) Analizar las situaciones de riesgo en los escenarios de la catástrofe.

b) Dar protección y seguridad a los afectados y equipos de emergencia.

c) Contribuir a establecer y custodiar un corredor sanitario para evacuar rápidamente a los heridos hacia los hospitales de referencia.

d) Asegurar la conservación y custodia de los bienes en riesgo.

e) Contribuir a la seguridad y custodia de los centros de mando y gestión de crisis.

f) Identificar a los fallecidos.

g) Mantener o restablecer el orden y la seguridad ciudadana.

h) Prevenir y actuar sobre la comisión de actos delictivos.

i) Investigar las causas y circunstancias del ataque, accidente o catástrofe.

j) Elaborar informes técnicos sobre las causas y circunstancias del suceso.

\subsection{Necesidades del Cuerpo de Bomberos}

a) Analizar las situaciones de riesgo (en los escenarios y en las estructuras siniestradas).

b) Proteger del entorno para prevenir accidentes posteriores y aumento de víctimas. Apuntalar o demoler viviendas, remover escombros y gestionar los riesgos detectados.

c) Participar en el rescate de las víctimas. Interviniendo cuando estén atrapadas por escombros, vehículos, lugares no accesibles, inundaciones, incendios- para dar acceso a los servicios médicos.

d) Extinción de incendios.

\subsection{Necesidades de los Servicios Médicos}

a) Disponer de un perímetro de seguridad para trabajar sin riesgos.

b) Instalar un espacio donde evaluar y atender a las víctimas (Puesto Médico Avanzado u Hospital de Campaña).

c) Disponer de un corredor sanitario para evacuar heridos.

d) Dar asistencia médica inmediata a los heridos según su gravedad.

e) Evacuar rápidamente a los heridos hacia los hospitales.

f) Filiar a heridos y fallecidos. Elaborar listados de heridos atendidos y centros sanitarios de derivación. Junto con los cuerpos de seguridad, confeccionar los listados de fallecidos. 


\subsection{Necesidades de los psicólogos sanitarios y del personal psicosocial}

a) Establecer un centro de recepción, información, atención y reagrupamiento para familiares, afectados o heridos leves con alta médica. Adaptando espacios para la atención médica, psicológica clínica y psicosocial.

b) Triage psicológico de los afectados. Evaluación rápida del estado psicológico de las victimas para identificar personas altamente afectadas, con reacciones sintomáticas anormales.

c) Detectar factores de riesgo psicológico en los afectados.

d) Brindar consejo sanitario y psicológico.

e) Hacer intervenciones clínicas y de orientación psicológica urgentes cuando se precise.

f) Derivar a los afectados que lo requieran a los centros de salud mental de la comunidad.

g) Detectar necesidades sociales en afectados y familiares y derivar a servicios sociales comunitarios cuando proceda.

h) Brindar atención psicosocial y de primeros auxilios psicológicos a los afectados.

i) Organizar la provisión del material necesario para cubrir las necesidades básicas de los afectados.

\subsection{Necesidades de los periodistas}

a) Resolver el dilema entre ayudar a las víctimas o cubrir la noticia. "Cuando los periodistas son los primeros en llegar a la escena se enfrentan a decisiones difíciles y peligros físicos y emocionales. Entre las cuestiones éticas a las que se enfrentan los periodistas están el ayudar a los heridos o evacuar gente antes de que los trabajadores de rescate lleguen a la escena [...] si el periodista se concentra en hacer su trabajo sin extender una mano a las víctimas, el público puede considerar esta acción moralmente inapropiada" (HiGHT y SMYTH, 2003: 12).

b) No arriesgar la vida. "Los supervisores deben plantearse la responsabilidad de mandar a reporteros y fotógrafos, especialmente jóvenes y sin experiencia, a situaciones potencialmente peligrosas" (Нight у SмYтH, 2003: 12-13).

c) Protegerse del peligro en el escenario. "Los periodistas de hoy en día deben tener presente el hecho de que ser los primeros en responder a un ataque violento o terrorista conlleva un riesgo significativo tanto físico como psicológico" (Hight y SMYTH, 2003: 13).

d) Protegerse del sufrimiento que genera el contacto con las víctimas. Los periodistas desplazados a escenarios de catástrofes corren el mismo riesgo de padecer estrés postraumático que otros profesionales en idénticas circunstancias y testigos y víctimas de hechos traumáticos (Mitchell et al., 2003: 14). "Los reporteros, fotógrafos, ingenieros, equipo de sonido y productores muchas veces trabajan hombro con hombro con los miembros de los equipos de emergencia. Los síntomas de estrés traumático que los periodistas muestran son extraordinariamente similares a los mostrados por oficiales de policía y bomberos que trabajan en período inmediatamente posterior a la tragedia, sin embargo, los periodistas reciben poco apoyo emocional después de haber mandado sus his- 
torias. Mientras a los trabajadores de seguridad pública se les ofrece sesiones informativas y orientación después de la tragedia, a los periodistas se les asigna la cobertura de otra historia" (Hight y SMYTH, 2003: 3). "Los periodistas [...] están expuestos al dolor. Mantener este dolor dentro sin buscar canales para el desahogo tal vez prolongue el impacto emocional y lo empeore en el futuro (...) y el hecho de que este desahogo pueda producirse en una etapa temprana depende de la existencia de un consejero/orientador contratado para esta tarea. Otorgar orientación profesional como parte del paquete de beneficios para los empleados puede contribuir a la producción de un periodismo más sensible y convincente" (Hight y SMYTH, 2003: 15).

e) Cubrir la noticia e informar.

f) Disponer de información veraz, científica y contrastada. La OMS exhorta al periodista que cubre catástrofes a "ser crítico con las fuentes de noticias. Comprobar los hechos cuidadosamente y distinguir entre la información oficial de la institución encargada del manejo de la emergencia y los criterios individuales de expertos, comentarios, descripción de hechos e interpretaciones" (RoDRÍGUEZ et al., 2006: 179).

g) Inmediatez. La inmediatez obstaculiza seriamente la información responsable y de calidad.

h) Transmitir mensajes institucionales de las instancias de gestión de la catástrofe. Para ello se recomienda "mantener un contacto sistemático con las instituciones de salud, para difundir información que ayude a mantener el equilibrio emocional de la población. Mantener informada a la población, de manera continua, sobre la evolución de la situación. Para esto es necesario transmitir en forma reiterada los mensajes importantes para la comunidad" (RoDRíGUEZ et al., 2006: 180).

i) Ayudar a explicar lo sucedido. Esta función primordial del periodista es criticada como ausente por los autores analizados, que coinciden en afirmar que se prioriza el emocionar en detrimento del explicar, analizar y comprender.

\subsection{Necesidades de los políticos}

a) Generar en la comunidad la percepción de que están trabajando para resolver la situación presente y actuando de cara al futuro.

b) Transmitir mensajes/informaciones útiles a la ciudadanía.

c) Gestionar y coordinar globalmente la crisis.

d) Instrumentalizar a la prensa para sus propios propósitos políticos.

e) Averiguar las causas de la catástrofe.

f) Diseñar medidas políticas, legislativas u otras para prevenir sucesos similares.

\section{Problemas detectados en el trabajo periodístico sobre catástrofes}

El análisis de la experiencia de los autores y de los equipos de intervención consultados para este artículo, permite detectar problemas importantes relacionados con el trabajo periodístico en escenarios de catástrofes. Mencionaremos los más notables. 
Sobre los escenarios del suceso se detecta en los periodistas:

a) Escasa capacitación y conocimientos sobre las dinámicas personales y organizativas propias de escenarios de catástrofe, que ocasiona interferencias, conflictos, desconfianza y dificultades para realizar un buen trabajo periodístico.

b) Actitudes prepotentes, irrespetuosas con víctimas y personal de emergencias, e inadecuadas para explicar sus intenciones y necesidades. Esto genera desconfianza entre los equipos de emergencia, que ven a los periodistas como sujetos que molestan, interfieren, estresan, engañan y manipulan informaciones y personas y no respetan el dolor de las víctimas ni los acuerdos que puedan pactarse.

c) Incapacidad/desconocimiento para generar vínculos con el personal de emergencia y con los afectados, cosa que dificulta o impide la labor informativa. La falta de vínculos y desconfianza impide que, por ejemplo, se les dé acceso a testimonios adecuados.

d) Escaso o nulo conocimiento sobre la psicología de las víctimas y sus necesidades y forma de abordaje si ello fuere posible. Con escasa sensibilidad y empatía se intenta entrevistar a cualquiera y en cualquier estado emocional con tal de personalizar la tragedia y frecuentemente las preguntas retraumatizan a la víctima.

e) La demanda profesional de inmediatez conlleva la transmisión de datos no contrastados y rumores que, aunque sean desmentidos, ocasionan perjuicios notables entre los afectados.

f) La necesidad de espectacularización lleva frecuentemente a prácticas que vulneran la ética, como esconder la identidad para mezclarse entre familiares u otros intervinientes para captar imágenes e informaciones "en caliente". El dolor de víctimas y allegados y las desavenencias entre equipos son objetivos bási$\cos$.

En las informaciones transmitidas se detecta:

a) Los aspectos ya reseñados por los autores citados (tendencia a la espectacularización, banalización, escabrosidad y estereotipos, falta de contexto explicativo y comprensivo, información no contrastada -perturbadora para los equipos operativos y los afectados (PUERTAS y VERA, 2006: 51)-, sobreexplotación inicial del suceso y pérdida rápida de interés noticioso, etc.).

b) Que raramente aportan información práctica, útil o sobre estrategias de afrontamiento y recursos personales y sociales que podría ayudar a los afectados, presentados como víctimas pasivas pero pocas veces autogestionando recursos.

c) Que la excesiva emocionalidad informativa, incluso cuando la realidad está normalizada, provoca activación emocional en víctimas y testigos pudiendo causar traumatización secundaria y revictimización, que también puede desencadenarse insistiendo en hechos traumáticos, dando protagonismo no buscado a víctimas-tipo o vulnerando la intimidad de las víctimas. 
Tras cubrir la catástrofe, en el periodista se detecta:

a) Que los responsables de medios no seleccionan ni forman a los periodistas que envían a un escenario de catástrofe. "Cualquier miembro de su sala de redacciones puede reaccionar de una manera distinta ante una situación traumática. A algunos les puede afectar inmediatamente, mientras que para otros la reacción puede tomar días, semanas, meses y aun años. Aquellos que aparentan no haber sido afectados pueden ser los que más se resientan del efecto de la experiencia. Otros pueden haber desarrollado formas de protección que les permitan contender con la tragedia y sufrir efectos mínimos" (Hight y SMYTH, 2003: 10). Prueba de esa irresponsabilidad de los directivos de medios la evidencian becarios enviados al escenario -algunos en su primer día de prácticas- y, especialmente, la asistencia de periodistas a consultas especializadas aquejados de estrés agudo o estrés postraumático desencadenado tras cubrir alguna catástrofe. Los autores tienen experiencia profesional en este ámbito, al que cabe añadir una dimensión no explorada: hablando con periodistas que han cubierto tragedias, un número significativo manifiesta tener, tiempo después, flashbacks con imágenes de cadáveres u otras, alteraciones del sueño, palpitaciones (activación emocional) cuando algo les recuerda su experiencia... esta sintomatología no atendida podría corresponderse con síntomas aislados de estrés postraumático.

b) Que no se forma a los periodistas para saber protegerse en un escenario de catástrofe; para tomar distancia emocional a la par que tener empatía; para compartir sentimientos y dolor con colegas y exteriorizar imágenes traumáticas que dañan si no se elaboran (HigHT y SMYTH, 2003: 8); para controlar el estrés (inevitable en estas situaciones) organizándose trabajo y descansos.

c) Que incluso periodistas muy avezados desconocen las sencillas y eficaces técnicas usadas por el personal de emergencias para desactivarse emocionalmente y afrontar el estrés y el trauma derivado de intervenir en escenarios de catástrofe.

\section{Discusión y conclusiones}

La crítica al modo de cubrir catástrofes y al discurso narrativo empleado es muy concreta por parte de los autores analizados, asumiendo que generalmente no se realiza un periodismo socialmente responsable -en el sentido citado en este artículo y que abarque el respeto a las necesidades de los implicados citadas sin perder independencia informativa- $\mathrm{y}$ que frecuentemente se incide negativamente en las dinámicas de trabajo de los grupos de intervención y en los procesos psicosociales de afectados, comunidades y receptores de información.

La relación entre periodistas y servicios de emergencia no es lo natural que podría parecerles a los primeros cuando los segundos advierten en sus manuales que: "el trabajo en desastres y emergencias incluye el enfrentamiento a situaciones estresantes, como [...] Presión por tener que trabajar ante la presencia de periodistas" (RoDRíGUEZ et al., 2006: 138).

Las interacciones que establecen los periodistas en escenarios de catástrofe deberían mejorarse en muchos aspectos, siendo preciso para ello adentrarse en un debate profe- 
sional y ético que module la tendencia al consumo de espectáculo propia de los medios actuales y que apueste por la formación específica de los periodistas dedicados a este ámbito, aspecto en el que serían útiles los códigos de actuación ya elaborados por diferentes instituciones y los manuales específicos que dan pautas para evitar los conflictos más frecuentes, por ejemplo, indicando formas adecuadas para entrevistar a afectados evitando su retraumatización (ZAPARDIEL y BALANZAT, 2009: 228-238).

Dar respuesta adecuada a las necesidades relacionadas en el apartado 3 y los problemas identificados en el apartado 4 abriría una vía de trabajo básica, pero aportar las propuestas apropiadas excedería en mucho las limitaciones de este artículo.

La traumatización de los afectados por catástrofes es un aspecto fundamental que no suele ser considerado por los periodistas, pero cabe recordar su incidencia: "alrededor del $30 \%$ de las personas se ven expuestas a lo largo de su vida a algún acontecimiento traumático. De este grupo, entre un 10 y un $20 \%$ desarrollan el trastorno" (Ríos, 2009: 21).

La insistencia de los autores en destacar este riesgo viene respaldada por su experiencia profesional, pero también por investigaciones específicas realizadas en este ámbito con resultados coincidentes. Así, al investigar la correlación entre el trastorno por estrés postraumático (TEPT) y la información sobre catástrofes se concluye que "la exposición a los medios de comunicación correlacionó significativamente con síntomas de reexperimentación e hiperactivación fisiológica [...] Estos resultados son consistentes con hallazgos previos que demostraban que la exposición a altos niveles de cobertura mediática incrementaba la sintomatología de estrés similar a la que se experimenta después de una vivencia traumática [...]. Puede ocurrir que la exposición repetida a las imágenes actúe como recordatorio del trauma y, en consecuencia, exacerbe la respuesta de estrés. A partir de ello, la hiperactivación y los síntomas de reexperimentación pueden actuar como desencadenantes de conductas de evitación" (ColLIMORE et al., 2008: 1026).

En la misma línea apuntada en este trabajo, ese riesgo "hace necesarias medidas preventivas para reducir la exposición mediática posterior a acontecimientos traumáticos de gran escala, particularmente con población vulnerable" (COLLIMORE et al., 2008: 1027).

Especialmente vulnerables son, tal como se indicó, los menores, cuya exposición a noticias catastróficas está significativamente relacionada con sus respuestas emocionales de miedo, preocupación, rabia o tristeza (BUIJzEN et al. 2007). Se ha investigado su afectación tras ser expuestos a informaciones sobre el 11-S, con hallazgos similares. Así, "se reportaron más síntomas de TEPT en menores que vieron noticias a través de Internet (vs. televisión/prensa), vieron imágenes con muertos o lesionados, o temieron por la muerte de una persona querida en los ataques. No produjo ningún beneficio el ver imágenes heroicas o "positivas". Los niños mayores y los muchachos estuvieron más expuestos a los medios y presentaron más síntomas específicos de TEPT" (SAYLOR et al. 2003: 1.622).

"Los síntomas de TEPT en respuesta al 11-S alcanzaron una tasa del 5,4\% en niños y de un $1,2 \%$ en sus madres. Los factores predictores de un mayor riesgo de sintomatología de TEPT fueron la identificación con las víctimas de los ataques en los 
niños y, en los más pequeños, la cantidad de televisión a la que estuvieron expuestos [...]. La visión de eventos trágicos es suficiente para producir síntomas de TEPT en poblaciones vulnerables tales como los niños" (Отто et al., 2007: 888).

Pero también los periodistas pueden verse afectados por estrés traumático, un problema silenciado y del que, más allá de experiencias profesionales, como la de los autores, o preocupaciones gremiales, como las expresadas desde el Dart Center for Journalism \& Trauma tras el 11-S (Hight y SмYTH, 2003), existe escasa investigación.

Resultan indicativos, no obstante, hallazgos como los de una investigación sobre periodistas de televisión japoneses, que concluye que: "el 6\% de los periodistas estudiados cumplieron criterios de TEPT potencial. Más aún, las reacciones de estrés postraumático en el momento de la encuesta se relacionaron con síntomas de estrés experimentados en el transcurso de reportajes estresantes. El asesoramiento precoz acerca de los síntomas de estrés en los periodistas que cubren noticias de catástrofes es importante para prevenir el desarrollo de TEPT" (HATANAKA et al., 2010: 177).

Aunque las investigaciones retrospectivas sobre trauma presentan problemas metodológicos insoslayables, no debe olvidarse que sus resultados son coincidentes y consistentes, aflorando un riesgo importante, para afectados y profesionales, que no puede obviarse en ningún planteamiento sobre periodismo socialmente responsable.

Finalmente, lo expuesto y discutido aquí requiere de futuras investigaciones específicas que amplíen nuestros conocimientos y permitan profundizar en propuestas que mejoren el ejercicio del periodismo en escenarios de catástrofes y su incidencia en la sociedad.

\section{Referencias bibliográficas}

ACINAS ACINAS, M. ${ }^{a}$ Patricia (2007): "Información a la población en situaciones de emergencia y riesgo colectivo". Intervención Psicosocial, n 3. Madrid, pp. 303321.

BERNARDO, José María y PELLISSER, Nel·lo (2010): “La 'naturalización’ mediática de las catástrofes. Una aproximación crítica". Cuadernos de Información, $\mathrm{n}^{\circ}$ 26. Santiago, Pontificia Universidad Católica de Chile, pp. 103-114.

BUIJZEN, Moniek; VAN DER MOLEN, Juliette H. Walma; SONDIJ, Patricia (2007): "Parental Mediation of Children's Emotional Responses to a Violent News Event". Communication Research, $\mathrm{n}^{\circ}$ 2, pp. 212-230.

CAMPS, Sibila y PAZOS, Luis (1996): Así se hace periodismo. Manual práctico del periodista gráfico. Buenos Aires, Paidós.

CAMPS, Sibila (1999): Periodismo sobre catástrofes. Buenos Aires, Ediciones Paulinas.

COLLIMORE, Kelsey C.; McCABE, Randi E.; CARLETON, R. Nicholas; ASMUNDSON, Gordon J.G. (2008): "Media exposure and dimensions of anxiety sensitivity: Differential associations with PTSD symptom clusters". Journal of Anxiety Disorders, $\mathrm{n}^{\circ}$ 22, pp. 1021-1028.

COTÉ, William y SIMPSON, Roger (2000): Covering Violence. A guide to ethical reporting about victims and trauma. New York, Columbia University Press. 
DE PABLOS COELLO, José Manuel y ELÍAS, Carlos (2003): "CSIC: chapapote de la ciencia española (o cómo se manipula información en catástrofes ecológicas)". Revista Latina de Comunicación Social, $\mathrm{n}^{\circ}$ 54. La Laguna (Tenerife), Universidad de la Laguna: http://www.ull.es/publicaciones/latina/200353chapapote.htm [fecha de consulta: 24 de enero de 2012].

DEKEL, Rachel y BAUM, Nehami (2010): "Intervention in a Shared Traumatic Reality: A New Challenge for Social Workers". British Journal of Social Work, $\mathrm{n}^{\circ} 40$. Oxford, Oxford University Press, pp. 1927-1944.

FERNÁNDEZ, Carolina (2004): “Guerras en el olvido", en Fusión, no 130, julio. La Vega-Riosa (Asturias): http://www.revistafusion.com/2004/julio/temac130.htm [fecha de consulta: 24 de enero de 2012].

GIL CALVO, Enrique (2003): El miedo es el mensaje. Madrid, Alianza.

HATANAKA, Miho; MATSUI, Yutaka; ANDO, Kiyoshi; INOUE, Kako; FUKUOKA, Yoshiharu; KOSHIRO, Eiko; ITAMURA, Hidenori (2010): "Traumatic Stress in Japanese Broadcast Journalists". Journal of Traumatic Stress, $n^{\circ}$ 1, pp. 173-177.

HATFIELD, Elaine, CACIOPPO, John y RAPSON, Richard (1994): Emotional Contagion. New York, Cambridge University Press.

HIGHT, Joe y SMYTH, Frank (2003): Tragedias \& Periodistas. Guía para una cobertura más eficaz. New York, Dart Center for Journalism \& Trauma and Columbia University: http://dartcenter.org/files/TragediasYPeriodistas.pdf [fecha de consulta: 24 de enero de 2012].

IMBERT, Gérard (2003): El zoo visual. De la televisión espectacular a la televisión especular. Barcelona, Gedisa.

KAPUSCINSKI, Ryszard (2000): Lapidarium IV. Barcelona, Anagrama.

LARRONDO URETA, Ainara (2006): "Del impacto mediático al olvido: la pérdida de interés noticioso como indicador de la deshumanización de los medios". Revista Latina de Comunicación Social, $\mathrm{n}^{\mathrm{0}}$ 61. La Laguna (Tenerife), Universidad de la Laguna: http://www.ull.es/publicaciones/latina/200612Larrondo.htm [fecha de consulta: 24 de enero de 2012].

LEVINE, Peter A. y FREDERICK, Ann (1999): Curar el Trauma. Barcelona, Urano.

LOZANO ASCENCIO, Carlos (2002): "La cultura del riesgo global a las catástrofes". Comunicación presentada al VII Congreso Iberoamericano de Comunicación. Maia, Oporto, Portugal. Noviembre de 2002.

LOZANO ASCENSIO, Carlos (2009): "Periodismo de catástrofes: La actualidad informativa como fuente de incertidumbres", en MORENO, Carolina (Ed.): Comunicar los riesgos. Ciencia y tecnología en la sociedad de la información. Madrid, Biblioteca Nueva, pp. 231-248.

MADARIAGA, Carlos (2002): Trauma psicosocial, trastorno de estrés postraumático y tortura. Santiago, Ediciones CINTRAS. 
MARAURI, Iñigo; RODRÍGUEZ, María del Mar; y CANTALAPIEDRA, María José (2011): "Géneros informativos y estilo periodístico en la cobertura de sucesos en la prensa diaria de información general en España (1977-2000)". Zer, nº 30. Leioa (Bizkaia), Universidad del País Vasco, pp. 213-227.

MITCHELL, Ann M., KAMEG, Kirstyn y SAKRAIDA, Teresa J. (2003): "Post-traumatic Stress: Clinical Implications". Disaster Management \& Response, $\mathrm{n}^{\mathrm{o}} 1$. Pittsburgh, pp. 14-18.

ORTEGA, Félix (2006): Periodismo sin información. Madrid, Tecnos.

OTTO, Michael W., HENIN, Aude, HIRSHFELD-BECKER, Dina R, POLLACK, Mark H., BIEDERMAN, Joseph, ROSENBAUM Jerrold F. (2007): "Posttraumatic stress disorder symptoms following media exposure to tragic events: Impact of 9/11 on children at risk for anxiety disorders". Journal of Anxiety Disorders, $\mathrm{n}^{\mathrm{0}} 7$, pp. 888-902.

OYANEDEL, Regina y ALARCÓN, Claudia (2010): "Una mirada al tratamiento televisivo de la catástrofe". Cuadernos de Información, $\mathrm{n}^{\circ}$ 26. Santiago, Pontificia Universidad Católica de Chile, pp. 115-122.

PUERTAS, Elena y VERA, Isabel (2006): "Dispositivo de Intervención Psicosocial en el incendio Forestal de la provincia de Guadalajara". Psicología sin Fronteras, $\mathrm{n}^{\circ}$ 2, pp. 41-51.

QUESADA, Montse (2007): Periodismo de sucesos. Madrid, Síntesis.

RINCÓN, Omar y RUÍZ, Martha (2002): "Más allá de la libertad. Informar en medio del conflicto". Signo y Pensamiento, $n^{\circ}$ 40. Bogotá, Pontificia Universidad Javeriana, pp. 72-86.

RÍOS BUSTOS, Mercedes (2009): “El trastorno por estrés postraumático y trastorno por estrés agudo en la influenza A (H1N1)". Vertientes, nº 1-2. México, pp. 20-23.

RODRÍGUEZ, Jorge; ZACCARELLI, Mónica; y PÉREZ, Ricardo (Ed., 2006): Guía práctica de salud mental en desastres. Washington, Organización Panamericana de la Salud/Organización Mundial de la Salud.

RODRÍGUEZ CÁRCELA, Rosa y MARTÍN RUIZ, M. Ángeles (2003): "Periodismo de catástrofes: el 11 de septiembre. Análisis del suceso y experiencias vividas". Ámbitos, $\mathrm{n}^{\circ}$ 9-10. Sevilla, Universidad de Sevilla, pp. 567-596.

ROTHSCHILD, Babette (2006): Help for the Helper: The Psychophysiology of Compassion Fatigue and Vicarious Trauma. New York, WW. Norton \& Company.

SAYLOR, Conway F.; COWART, Brian L.; LIPOVSKY, Julie A.; JACKSON, Crystal; FINCH, A. J. (2003): "Media Exposure to September 11 Elementary School Students' Experiences and Posttraumatic Symptoms". American Behavioral Scientist, $\mathrm{n}^{\mathrm{o}} 12$, pp. 1.622-1.642.

ZAPARDIEL FERNÁNDEZ, Ana y BALANZAT ALONSO, Syra (2009): Manual de intervención psicológica y social en victimas de terrorismo: 11-M. Madrid, Asociación de Ayuda a las Victimas del 11M. 